\title{
Perforation with retroperitoneal emphysema after endoscopic submucosal dissection for a rectal carcinoid tumor
}

A 49-year-old woman was admitted to our hospital for treatment of a rectal carcinoid tumor ( $\bullet$ Fig. 1 ).

Conventional endoscopic submucosal dissection (ESD) was carried out ( $\bullet$ Fig. 2) during which a perforation occurred.

The hole was immediately closed using endoclips ( $\bullet$ Fig. 3).

On the following day, however, the patient developed high fever and slight abdominal pain. Computed tomography (CT) revealed a large amount of air in the retroperitoneal and mediastinal spaces (๑ Fig. 4).

On the next day, her C-reactive protein (CRP) level was elevated $(41 \mathrm{mg} / \mathrm{dL})$. Oral intake was withheld, and antibiotics were administered for 14 days. A follow-up CT examination on day 8 showed that the amount of air had decreased. Oral feeding was resumed on day 10 . The patient was discharged 19 days after the procedure. Histological examination of the endoscopy specimen revealed that the resection margin was negative for tumor cells. Histologically, no muscular propria tissue was present in the specimen. Although the patient continued to have back pain and slight fever for some time, she recovered fully over a period of several months. Rectal carcinoid tumors occur as small, solitary, submucosal nodules, but standards of treatment are still controversial $[1,2]$. If the tumor size is $10 \mathrm{~mm}$ or less, the tumor can be resected using endoscopic local excision techniques. ESD was originally developed as a technique for en bloc endoscopic resection, but a recent report described this method as an effective

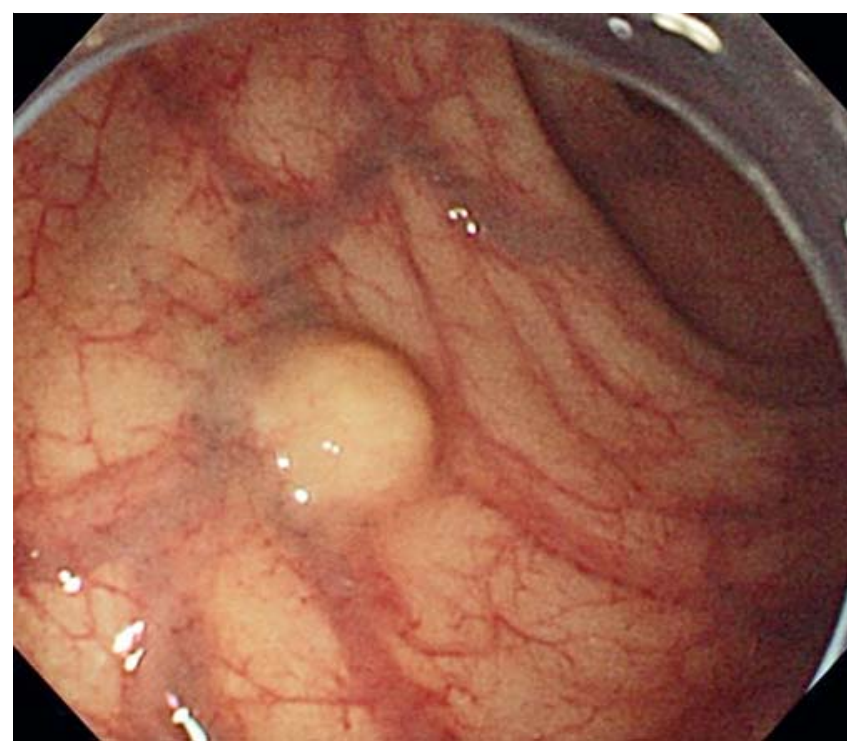

Fig. 1 Endoscopic view of an $8 \mathrm{~mm}$ rectal carcinoid tumor.

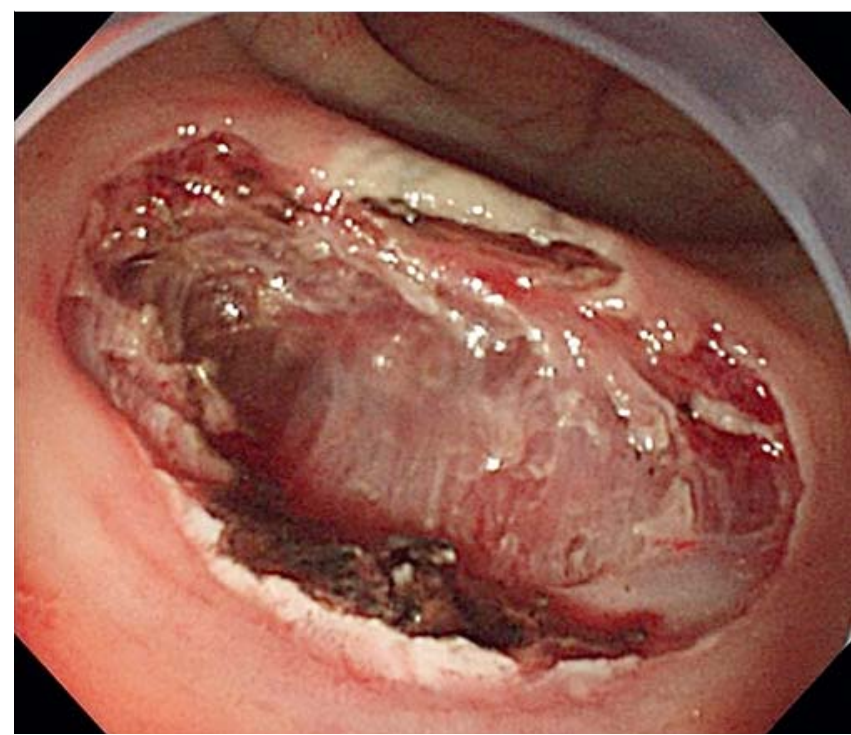

Fig. 2 Endoscopic view of the mucosectomy site after endoscopic submucosal dissection (ESD). and safe treatment for rectal carcinoid tumors [3]. The most risky ESD-related complication is perforation, which can have serious consequences. Therefore, the greatest care should be taken in the management of such perforations.

Endoscopy_UCTN_Code_CPL_1AH_2AZ 

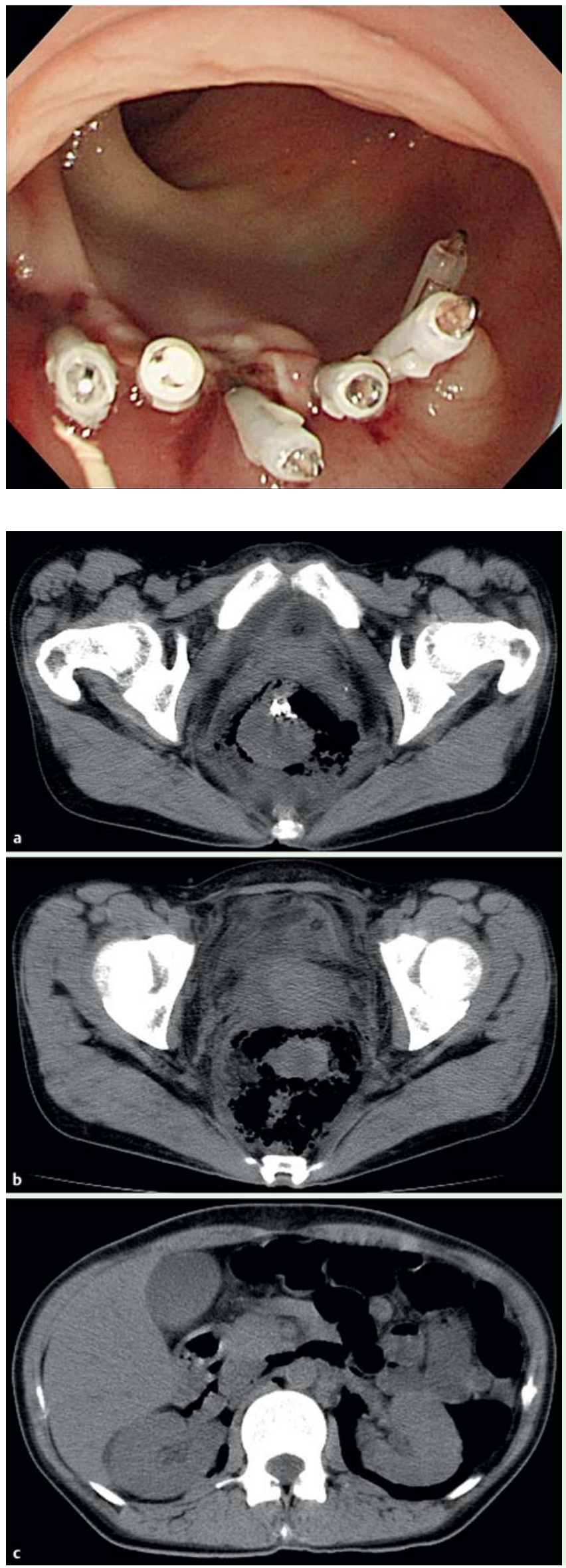

Fig. 3 After endoscopic submucosal dissection (ESD) the site was closed using endoclips to prevent delayed perforation.

H. Chiba ${ }^{1}$, K. Ohata ${ }^{1}$, A. Ohno ${ }^{1}$, Y. Sekino ${ }^{1}$, T. Ito ${ }^{1}$, Y. Tsuji ${ }^{1}$, T. Ohya ${ }^{1}$, M. Inamori ${ }^{2}$, A. Nakajima ${ }^{2}$, N. Matsuhashi ${ }^{1}$

Department of Gastroenterology, Kanto Medical Center, NTT East, Tokyo, Japan

2 Gastroenterology Division, Yokohama City University School of Medicine, Yokohama, Japan

\section{References}

1 Ono A, Fujii T, Saito $Y$ et al. Rectal carcinoid tumors: endoscopic submucosal resection with a ligation device. Gastrointest Endosc 2003; 57: $583-587$

2 Charles B, Irina J, Edvardas $K$ et al. "Bandsnare" resection of small rectal carcinoid tumors. Gastrointest Endosc 1999; 50: 582 585

3 Ishii $N$, Itoh $T$, Takayanagi $M$ et al. Endoscopic submucosal dissection for small rectal carcinoid tumors. Gastrointest Endosc 2006; 63: AB219

Fig. 4 a-c Computed tomography (CT) revealed a large amount of free air in the retroperitoneal and mediastinal spaces.
4 Fujishiro M, Yahagi N, Kakushima N et al. Successful nonsurgical management of perforation complicating endoscopic submucosal dissection of gastrointestinal epithelial neoplasms. Endoscopy 2006; 38: $1001-1006$

\section{Bibliography}

DOI $10.1055 / \mathrm{s}-0029-1243873$

Endoscopy 2010; 42: E85-E86

(c) Georg Thieme Verlag KG Stuttgart · New York . ISSN 0013-726X

\section{Corresponding author}

\section{Inamori, MD}

Gastroenterology Division

Yokohama City University School of Medicine 3-9 Fukuura

Kanazawa-ku

Yokohama 236-0004

Japan

Fax: +81-45-7843546

inamorim@med.yokohama-cu.ac.jp 